\title{
Purification and characterization of antibacterial proteins from granular hemocytes of Indian mud crab, Scylla serrata
}

\author{
Roshan Dinesh Yedery and Kudumula Venkata Rami Reddy ${ }^{凶}$ \\ Department of Molecular Immunology, National Institute for Research in Reproductive Health (ICMR), \\ Mumbai, India
}

Received: 28 August, 2008; revised: 02 December, 2008; accepted: 09 January, 2009 available on-line: 12 Fabruary, 2009

\begin{abstract}
Marine invertebrates depend upon antimicrobial peptides (AMPs) as a major component of innate immunity, as they are rapidly synthesized and diffuse upon pathogen invasion. In this study, we report the identification and characterization of a $11 \mathrm{kDa}$ antimicrobial protein, which we name SSAP (for Scylla serrata antimicrobial protein), from granular hemocytes of the mangrove crab $S$. serrata. The protein is highly similar to scygonadin, a male-specific AMP isolated from the ejaculatory duct of $S$. serrata. SSAP was isolated using various chromatographic techniques, viz. ion-exchange, ultra filtration and RP-HPLC, and demonstrated antibacterial activity against Gram positive and Gram negative bacteria. Full length mRNA encoding SSAP was amplified using a combination of RT-PCR and RACE. The nucleotide sequence revealed a full-length ORF of $381 \mathrm{bp}$ coding for a preprotein of $\mathbf{1 2 6}$ amino acids comprising a signal peptide of 24 amino acids and a mature protein of 102 amino acids with a predicted mass of $11435 \mathrm{Da}$ and $\mathrm{pI}$ of 5.70. Unlike scygonadin, SSAP is expressed in several tissues of both male and female crabs, as evidenced by RT-PCR, Northern and Western blot analyses. The study suggests that SSAP might be an isoform or a variant of scygonadin and might play an important role in regulating the immunity of the crab upon microbial infection.
\end{abstract}

Keywords: antibacterial protein, crab, Scylla serrata, hemocytes, innate immunity

\section{INTRODUCTION}

The invertebrates comprise over $95 \%$ of animal species and some live in environments rich in potentially harmful microorganisms. As a result these animals have developed various competent strategies to defend their lives against invading pathogens (Jiravanichpaisal et al., 2006). Earlier reports have substantiated the fact that invertebrates lack the complexity of the adaptive immune system characterized by memory and depend solely on non specific innate immune responses of amazing diversity and evolutionary success. Recent experimental data from invertebrates suggests that past exposure to pathogens in individual animals can lead to enhanced immunity and some are also known to have considerable specificity by recognizing non-self pathogen-associated molecules through a series of pattern recognition receptors that are highly conserved in evolution (Janeway \& Medzhitov, 2002; Kurtz, 2005). These reports corroborate the existence of both specificity and memory in invertebrates.

\footnotetext{
$\square$ Corresponding author: K.V.R. Reddy, Department of Molecular Immunology, National Institute for Research in Reproductive Health (ICMR), J. M. Street, Parel, Mumbai - 400 012, India; fax: (91) 0222413 9412; tel: (91) 022 2419 2016/2126/2000; e-mail: reddyk@nirrh.res.in

Abbreviations: AMPs, antimicrobial peptides; BSA, bovine serum albumin; BV, bacterial vaginosis; CMC, carboxymethyl cellulose; CSPD, disodium 3-[4-metoxyspirol (1,2-dioxetane-3,2'-(5'-chloro)tricyclo)decan]phenyl phosphate; LB, Luria-Bertani broth; MHB, Mueller-Hinton broth; MIC, minimal inhibitory concentration; ORF, open reading frame; PI, protease inhibitor cocktail; RP-HPLC, reversed phase high pressure liquid chromatography; RT-PCR, reverse transcriptase polymerase chain reaction; RACE, rapid amplification of cDNA ends; SDS/PAGE, sodium dodecyl sulphate polyacrylamide gel electrophoresis; SSAP, Scylla serrata antimicrobial protein; STI, sexually transmitted infection; TFA, trifluroacetic acid.
} 
Some of the known innate immune responses in invertebrates include pahogocytosis, nodulation and encapsulation, synthesis of (AMPs) and activation of proteolytic cascades that lead to melanization, blood coagulation, release of stress-responsive proteins and molecules believed to function in opsonization and iron sequestration (Lee \& Soderhall, 2002; Iwanaga \& Lee, 2005).

AMPs are a major component of the innate immune defense system in marine invertebrates. These molecules are the first line of host defense in various species, have a mass of $\leq 10 \mathrm{kDa}$ and are readily synthesized and efficiently diffuse at the point of pathogen entry or infection, hence form an invaluable component of the innate immune system (Reddy et al., 2004a, 2004b; Cole, 2005). AMPs have also been shown to demonstrate in vitro microbicidal properties against various clinical pathogens, including the sexually transmitted infection (STI)-causing Treponema pallidum, Chlamydia trachomatis and HIV (Yedery \& Reddy, 2005). These peptides have been isolated from a wide variety of vertebrate and invertebrate phyla including mammals, reptiles, ascidians, insects, chelicerates, annelids and mollusks (Andreu \& Rivas, 1998; Cooper, 1985; Lehrer \& Ganz, 1999). In particular, several AMPs have been identified from a variety of marine invertebrate species. Tachyplesins and polyphemusins are two well characterized cationic molecules from granular hemocytes of Japanese horseshoe crab (Tachypleus tridentatus) and American horseshoe crab (Limulus polyphemus), respectively (Miyata et al., 1989; Murakami et al., 1991). Prominent among AMPs isolated from crustaceans are penaeidins from the shrimp Penaeus vannamei, while in marine mollusks, defensins, myticins and mytilins isolated from Mytilus galloprovincialis and Mytilus edilus, respectively, have been studied for their specific roles in innate immune mechanisms (Mitta et al., 2000).

Scylla serrata, commonly known as the mud crab or mangrove crab, is an economically important marine invertebrate distributed throughout the West Pacific and Indian Oceans. This crab inhabits muddy bottoms of brackish water along the shoreline, mangrove areas, and river mouths, hence the name mud crab or mangrove crab. It is the most important edible crab for commercial culture in the Indo-West Pacific region and commands a high price in both the domestic and export markets (Samonte \& Agbayani, 1992). The crabs are in intimate contact with an environment rich in pathogenic bacteria, and are prone to infection by microbes at various stages of growth, losses due to disease can be enormous (Hudson \& Lester, 1994). Hence there is an urgent need to understand the existing defense mechanisms in such animals and find ways of enhancing their natural immunity against infectious pathogens.
Earlier, Chattopadhyay and Chatterjee (1997) described the isolation and characterization of scyllin, an antimicrobial lectin from the hemolymph of S. serrata, while Hoq and colleagues (2003) identified various protein fractions from the hemolymph of $S$. serrata that demonstrated antimicrobial activity against various Gram positive and Gram negative bacteria. Recently, Huang and colleagues (2006) have isolated a $10.8 \mathrm{kDa}$ anionic protein named scygonadin from the male reproductive tract of $S$. serrata that inhibited growth of Micrococcus luteus and Aeromonas hydrophila. The present study demonstrates the identification of about $11 \mathrm{kDa}$ antimicrobial protein from hemocytes of $S$. serrata, SSAP, which shows high sequence similarity with scygonadin. Preliminary comparisons of cDNA and translated protein sequences strongly indicate that SSAP could possibly be a variant of scygonadin. Recent reports have postulated the possibility of using AMPs as vaginal microbicidal compounds to combat the spread of STI and HIV (Cole, 2005). Hence in our present study all antimicrobial assays were carried out with vaginal bacterial isolates from women suffering from bacterial vaginosis $(\mathrm{BV})$.

\section{MATERIALS AND METHODS}

Experimental animals. Specimens of the common Indian mud crab, S. serrata, were purchased from the local fish market and kept in a glass tank with seawater until further use. They were fed twice daily with minced fish meat. Both male and female, healthy intermoult animals $(7 \pm 1$ $\mathrm{cm}$ carapace width) were used. Each animal was subjected to a single bleed amounting to $3-4 \mathrm{ml}$ of hemolymph.

Microbial strains and culture. Vaginal isolates of Gram negative bacteria Escherichia coli and Pseudomonas aeruginosa, and Gram positive bacteria Staphylococcus aureus and Streptococcus pyogenes were obtained from the Microbiology Department of King Edwards Memorial Hospital (Mumbai, India). The strains were isolated from vaginal swab cultures of women tested positive for BV, were identified by Gram staining and characterized biochemically. The organisms were grown in MHB (Hi-Media Laboratories, Mumbai, India) at $37^{\circ} \mathrm{C}$ for $18 \mathrm{~h}$ and then subcultured into fresh broth and raised to log phase for 4-6 h. Log phase bacteria were harvested by centrifuging at $2000 \times \mathrm{g}\left(10 \mathrm{~min}, 4^{\circ} \mathrm{C}\right)$ and were washed twice in sterile physiological saline $(0.9 \%$ $\mathrm{NaCl}$ ) before final resuspension in fresh sterile saline. All bacterial suspensions were calibrated and routinely standardized to an absorbance of 0.4 at $570 \mathrm{~nm}$, which gave a concentration of approx. $10^{9}$ c.f.u. $\mathrm{ml}^{-1}$. 
Antibacterial assays. Antibacterial activity of purified fractions obtained at each step of purification was assessed by a two-layer radial diffusion method described earlier by Relf and coworkers (1999). Briefly, the modified protocol involves preparing a $14-\mathrm{ml}$ bacterial underlay of $1 \%$ agarose in $10 \% \mathrm{MH}$ broth supplemented with $0.02 \%$ Tween in a $12 \times 12 \mathrm{~cm}$ Petri dish. The agar was seeded with $1 \times 10^{6}$ washed bacteria. Wells of $3 \mathrm{~mm}$ diameter were punched into the agarose and $50 \mu \mathrm{l}$ of the test sample was pipetted into each. Negative controls comprised only sterile deionized water containing $0.1 \%$ acetic acid. The plates were incubated at $4^{\circ} \mathrm{C}$ for $3 \mathrm{~h}$ and then overlaid with $14 \mathrm{ml}$ of sterile $1 \%$ agarose containing double strength LBB. They were incubated for a further $24 \mathrm{~h}$ at $35^{\circ} \mathrm{C}$. Clear zones in the agar underlays were taken as indicating antibacterial activity. Their diameters were measured and activity was expressed as clear zone area (in $\mathrm{mm}^{2}$ ) minus the area of the well.

Determination of the minimal inhibitory concentrations (MICs). Minimal inhibitory concentrations of purified SSAP were determined against Gram negative bacteria E. coli and P. aeruginosa and Gram positive bacteria $S$. aureus and S. pyogenes in sterilized 96-well plates (NUNC, Roskilde, Denmark) in a final volume of $100 \mu \mathrm{l}$ composed of $50 \mu \mathrm{l}$ of $10^{6}$ bacteria in $\mathrm{MH}$ broth and $50 \mu \mathrm{l}$ of SSAP in serial two fold dilutions $\left(6.25-200 \mu \mathrm{g} \mathrm{ml}^{-1}\right)$ in sterile water containing $0.1 \%$ acetic acid. Wells without protein were used as a negative control. The plates were left with shaking (90 r.p.m.) at $37^{\circ} \mathrm{C}$ and bacterial growth was assayed by measurement of the optical density at $600 \mathrm{~nm}$ after 24-h incubation. The MIC values are expressed as described by Casteels et al. (1993).

Preparation of granular hemocyte extract. Fresh hemolymph was collected aseptically from crabs of either sex with a 21 gauge needle attached to a syringe, by puncturing into the heart from the dorsal surface of the carapace. The hemolymph was diluted with equal volume of sterile marine anticoagulant $(0.14 \mathrm{M} \mathrm{NaCl}, 0.1 \mathrm{M}$ glucose, $30 \mathrm{mM}$ trisodium citrate, $36 \mathrm{mM}$ citric acid and $10 \mathrm{mM}$ EDTA, pH 4.6). Granular hemocyte populations were separated on a $60 \%$ continuous Percoll gradient as described elsewhere (Soderhall \& Smith, 1983). The granular cell band was removed with a sterile Pasteur pipette and transferred into a $50-\mathrm{ml}$ polycarbonate tube containing an equal volume of marine anticoagulant supplemented with complete protease inhibitor cocktail (PI) (Roche, Mannheim, Germany). The cells were pelleted by centrifugation at $1900 \times \mathrm{g}\left(10 \mathrm{~min}, 4^{\circ} \mathrm{C}\right)$ and the supernatant discarded.

The cells were suspended in $2.5 \mathrm{ml}$ of sterile saline containing PI and incubated on ice for 20 min followed by lysis of cells with an ultrasonica- tor (Remi Instruments, Mumbai, India) for $10 \mathrm{~min}$. The sample was centrifuged at $12000 \times g$ ( $20 \mathrm{~min}$ at $4^{\circ} \mathrm{C}$ ) and the supernatant stored overnight at $-20^{\circ} \mathrm{C}$. The pellet was resuspended in $2.5 \mathrm{ml}$ of $10 \%$ acetic acid containing PI and incubated overnight at $4^{\circ} \mathrm{C}$ followed by centrifugation at $12000 \times g$. After further centrifugation, the two supernatants were pooled and dialyzed using the Amicon ultrafiltration units with a $3 \mathrm{kDa}$ cut-off membrane (Millipore, Bedford, MA, USA) with two washes with $0.2 \mathrm{M}$ sodium acetate $(\mathrm{pH} 4.0)$. Protein concentration was determined by the method of Bradford (1976) using bovine serum albumin as a standard.

Purification of antimicrobial proteins. Ion exchange chromatography was performed as described by Zasloff (1987). The dialyzed extract of granular hemocytes $(5 \mathrm{ml})$ was loaded onto a $36 \times 2.8 \mathrm{~cm}$ glass column packed with carboxymethyl cellulose (Sigma, St. Louis, MO, USA), equilibrated with $0.2 \mathrm{M}$ sodium acetate $(\mathrm{pH} 4.0)$ buffer. Unbound proteins were washed off with sodium acetate until the absorbance returned to baseline. Bound proteins were eluted with $0.2 \mathrm{M}$ ammonium acetate buffer ( $\mathrm{pH}$ 5.2). Fractions $(2 \mathrm{ml})$ were collected and their absorbance was monitored at $280 \mathrm{~nm}$ using a spectrophotometer (UV-160A, Shimadzu, Japan). Protein fractions were freeze-dried, dissolved in $50 \mu \mathrm{l}$ of sterile deionized water containing $0.1 \%$ acetic acid and tested for antibacterial activity. Fractions demonstrating antibacterial activity were pooled and loaded onto an Amicon ultrafiltration unit with a $30 \mathrm{kDa}$ cut-off membrane (Millipore, Bedford, MA, USA). The unit was centrifuged at $5000 \times g$ for $30 \mathrm{~min}$ and the filtrate was lyophilized.

The lyophilized sample was acidified to a final concentration of $0.1 \%$ TFA and applied onto a $22 \times 250 \mathrm{~mm}$ Vydac $\mathrm{C}_{8}$ RP-HPLC column (Hesperia, CA, USA). Adsorbed proteins were eluted $(1 \mathrm{ml} /$ $\mathrm{min}$ ) in a three-step gradient of $0.1 \% \mathrm{TFA} /$ water and $0.1 \%(\mathrm{v} / \mathrm{v})$ TFA in $50 \%$ acetonitrile: $0-100 \%$ (60 min), held at $100 \%$ for $5 \mathrm{~min}$ and brought back to $0 \%(100-0 \%)$. The absorbance of the fractions was monitored at $280 \mathrm{~nm}$ and they were freeze-dried. The samples were dissolved in $50 \mu \mathrm{l}$ of sterile deionized water containing $0.1 \%$ acetic acid and assayed for antibacterial activity. Fractions with antibacterial activity were loaded further on the same column to check for homogeneity. The above purification protocol was repeated a number of times to obtain bulk amount of active protein. The active protein was termed SSAP.

SDS/polyacrylamide gel electrophoresis. One dimensional SDS/PAGE (Laemmli, 1970) was performed using a vertical slab gel apparatus (Biorad, Hercules, CA, USA) with the stacking gel containing 3\% acrylamide and the resolving gel with 15\% acrylamide. Briefly, the RP-HPLC-purified SSAP 
fractions were diluted with reducing sample buffer (20\% glycerol, 1\% SDS, $0.125 \mathrm{M}$ Tris/HCl, $2 \% \beta$-mercaptoethanol and $0.5 \%$ bromophenol blue), heated for $5 \mathrm{~min}$ at $100^{\circ} \mathrm{C}$ and centrifuged at $10000 \times g$ for 5 min. The supernatant was loaded into a single well and subjected to electrophoresis. The gel was calibrated using molecular mass markers (Amersham Biosciences, Piscataway, NJ, USA) and stained with silver nitrate (Sigma, St. Louis, MO, USA).

Protein sequencing. Fractions containing the purified SSAP were subjected to trypsin digestion using $0.2 \mu \mathrm{g}$ of modified trypsin (Pierce, Rockford, IL, USA) for $18 \mathrm{~h}$ at $37^{\circ} \mathrm{C}$. Cysteines were modified by reducing the protein in $100 \mathrm{mM}$ ammonium bicarbonate containing $0.25 \%(\mathrm{v} / \mathrm{v})$ 2-mercaptoethanol for 30 $\min$ at $65^{\circ} \mathrm{C}$. Then the protein was treated with iodoacetamide (final concentration $0.35 \mathrm{mM}$ ) and incubated for $30 \mathrm{~min}$ at room temp. The mixture was desalted on a $3 \mathrm{kDa}$ cut-off centriprep filter (Millipore, Bedford, MA, USA) and the resulting peptides were separated on a $22 \mathrm{~mm} \times 250 \mathrm{~mm}$ Vydac $\mathrm{C}_{8}$ RP-HPLC system. Selected peptide peaks were subjected to sequence analysis by automated Edman degradation using a Procise protein sequencing system (Applied Biosystems, Foster City, CA, USA).

RNA isolation from hemocytes. Granular hemocytes were separated from freshly drawn hemolymph as described earlier. Total RNA was extracted from $0.5 \mathrm{ml}$ of undiluted granular hemocytes by homogenization with an ultrasonicator (Remi Instruments, Mumbai, India) for $5 \mathrm{~min}$ in $1 \mathrm{ml}$ of ice cold Trizol (Roche, Mannheim, Germany). The sample was brought to room temp. and mixed with $0.2 \mathrm{ml}$ of chloroform. The tube was shaken vigorously for $15 \mathrm{~s}$ and incubated at room temp. for $2 \mathrm{~min}$ before centrifugation at $12000 \times \mathrm{g}\left(15 \mathrm{~min}, 4^{\circ} \mathrm{C}\right)$. The upper, aqueous phase containing RNA was transferred to a fresh tube and the nucleic acid precipitated by mixing with $0.25 \mathrm{ml}$ of absolute isopropanol for $10 \mathrm{~min}$ at room temp. The pellet remaining after centrifugation at $12000 \times \mathrm{g}\left(10 \mathrm{~min}, 4^{\circ} \mathrm{C}\right)$ was washed once with $1 \mathrm{ml}$ of $75 \%$ ethanol, mixed by vortexing and re-centrifuged at $7500 \times g\left(5 \mathrm{~min}, 4^{\circ} \mathrm{C}\right)$. The RNA obtained was checked for purity by spectrophotometer at $\mathrm{A}_{260} / \mathrm{A}_{280} \mathrm{~nm}$ (Schimadzu, Japan). The quality and integrity of RNA was further determined by $1.2 \%$ denaturing formaldehyde/agarose gel electrophoresis. The resulting RNA $\left(\mathrm{A}_{260 /} \mathrm{A}_{280}: 1.74\right.$, concn.: 800 $\mu \mathrm{g} \mathrm{m} \mathrm{m}^{-1}$ ) was dried at room temp. for $5 \mathrm{~min}$ and then redissolved in $50 \mu \mathrm{l}$ of DEPC water.

Design of degenerate primers and RT-PCR. Full-length cDNA of SSAP was obtained by the procedures of RT-PCR and RACE method. For this purpose degenerate primes were designed from two of the known amino-acid sequences, the forward degenerate primer DF (5'-CCNGAYGGNTTYTAYACN$\left.3^{\prime}\right)$ was designed from the peptide PDGFYT, and the reverse degenerate primer DR (5'-YTTNARNGCYTCTARYTC-3') was designed from the peptide ELEALK. RT-PCR was performed with $2-3 \mu \mathrm{g}$ of hemocyte total RNA with primers DF and DR, using Qiagen one step RT-PCR kit (Qiagen, Valencia, CA, USA) according to the manufacturer's instructions. The PCR reaction included an initial RT reaction at $50^{\circ} \mathrm{C}$ for $30 \mathrm{~min}$ followed by PCR activation step at $95^{\circ} \mathrm{C}$ for $15 \mathrm{~min}$, followed by 35 cycles at $94^{\circ} \mathrm{C}$ for $30 \mathrm{~s}$, annealing at $55^{\circ} \mathrm{C}$ for $30 \mathrm{~s}$, extension at $72^{\circ} \mathrm{C}$ for $30 \mathrm{~s}$ and a final extension at $72^{\circ} \mathrm{C}$ for $10 \mathrm{~min}$. PCR products were separated on a $2.0 \%$ agarose gel.

The resulting about $100 \mathrm{bp}$ PCR product was excised from the gel using a QIA quick gel extraction kit (Qiagen, Valencia, CA, USA). The purified product was ligated into pMOSBlue vector (Amersham Biosciences, Piscataway, NJ, USA) and transformed into E. coli, DH5 $\alpha$ competent cells and incubated overnight at $37^{\circ} \mathrm{C}$. Positive clones were isolated by blue/white screening. Single white colonies were picked individually and grown over night for plasmid preparation. Plasmid DNA was purified using Qiagen Plasmid Purification Kit as per the manufacturer's instructions and sequenced using T7 and M13 promoter primers on an ABI PRISM 377 DNA sequencer (Applied Biosystems, Foster City, CA, USA).

5' and 3' RACE PCR. Five micrograms of hemocyte total RNA was reverse transcribed to prepare 5' and 3' RACE Ready cDNA using SMART ${ }^{\mathrm{TM}}$ RACE cDNA Amplification kit (Clontech, Mountainview, CA, USA) according to manufacturer's recommendations. To obtain the sequence of fulllength SSAP cDNA from S. serrata, $3^{\prime}$ and $5^{\prime}$ RACE PCR were performed using gene-specific primers based on the about $100 \mathrm{bp}$ fragment that was obtained from RT-PCR analysis. For 5' RACE PCR, a $50 \mu \mathrm{l}$ reaction was set up containing $5 \mu \mathrm{l} 5^{\prime} \mathrm{RACE}$ cDNA and primers UP1 (5'-CTAATACGACTCACTATAGGGCAAGCAGTGGTATCAACGCAGAGT $\left.-3^{\prime}\right)$ and SR (5'-AACCCGGCTTCTTCCTTC-3'). The first PCR conditions were as follows: $5 \mathrm{~min}$ initial denaturation at $94^{\circ} \mathrm{C}$ for one cycle, then 30 cycles of denaturation at $94^{\circ} \mathrm{C}$ for $30 \mathrm{~s}$, primer annealing at $58^{\circ} \mathrm{C}$ for $30 \mathrm{~s}$ and extension at $72^{\circ} \mathrm{C}$ for $1 \mathrm{~min}$, and finally $10 \mathrm{~min}$ final extension at $72^{\circ} \mathrm{C}$. The products were analyzed on agarose gels.

The nested 5' PCR was carried out with $5 \mu \mathrm{l}$ of 1:50 dilution of the above PCR product and primers UP2 (5'-AAGCAGTGGTATCAACGCAGAGT-3') and SR using the same conditions as above. The $5^{\prime}$ nested PCR product of the predicted size was gelseparated, purified, inserted into the pMOSBlue vector, and the positive clones were sequenced.

The 3' RACE PCR was carried out with 3' RACE CDNA and primers UP1 and SF (5'-TGTGGTGTACTTCCTGGA-3'), and the nested 3' PCR was 
carried out with primers UP2 and SF using the same conditions as above. The annealing temperature used in the reaction was $60^{\circ} \mathrm{C}$. The products were cloned and sequenced as above.

Sequence analysis. The full-length cDNA of SSAP was compared with default settings with the complete non-redundant GenBank database using the BLAST program available at the NCBI website (http://www.ncbi.nlm.nih.gov/blast/). The full length SSAP cDNA sequence was translated to a predicted amino-acid sequence using ExPASy proteomic tool (http://www.expasy.org/tools/dna. html). The putative cleavage site of the signal peptide was predicted by SignalP (http://www. cbs.dtu.dk/services/SignalP/). Both the mass and the $\mathrm{pI}$ of the putative protein were calculated using the ProtParam tool by ExPASy (http://www. expasy.org/tool/protparam). The hydropathy plot of the deduced amino-acid sequence was plotted using the method of Kyte and Doolittle (http:// fasta.bioch.virginia.edu/fasta_www2/fasta_www. cgi? rm=misc1).

Expression study. Healthy crabs (both male and female) were dissected and their gills, heart, hepatopancreas, reproductive tract, muscle, hemocytes, eyes and digestive tract were carefully collected aseptically and stored at $-80^{\circ} \mathrm{C}$. Total RNA was extracted using Trizol as described earlier. To analyze the tissue expression pattern of SSAP, RTPCR was performed with 1-2 $\mu \mathrm{g}$ of hemocyte total RNA with ORF-specific primers OF (5'-ATGCGTTCATCTCTCTACTC-3') and OR (5'-CCCGACCATATAAATTATGGC-3'), using Qiagen one step RT-PCR kit. The PCR program was as follows: one cycle at $95^{\circ} \mathrm{C}$ for $2 \mathrm{~min}, 35$ cycles of $94^{\circ} \mathrm{C}$ for $20 \mathrm{~s}$, $55^{\circ} \mathrm{C}$ for $30 \mathrm{~s}$ and $72^{\circ} \mathrm{C}$ for $20 \mathrm{~s}$, followed by a cycle at $72^{\circ} \mathrm{C}$ for $2 \mathrm{~min}$. Primers for actin, CF (5'-CGTTCGTGACATCAAGGAGA-3') and CR (5'-AGGAAGGAAGGCTGGAAGAG-3') were used in a positive control reaction. The PCR products were analyzed on a $1.5 \%$ agarose gel, eluted and digoxigenin (DIG) labeled by DIG DNA Labeling Kit (Roche, Mannheim, Germany).

Northern blot analysis. For Northern blot analysis, $30 \mu \mathrm{g}$ of RNA from the above-mentioned tissues, including hemocytes, was denatured in formaldehyde-containing buffer and incubated at $68^{\circ} \mathrm{C}$ for $15 \mathrm{~min}$, then electrophoresed. The RNA was transferred onto a Hybond $\mathrm{N}+$ membrane (Amersham Biosciences, Piscataway, NJ, USA) by using conventional capillary blotting in $20 \times$ SSC buffer ( $3 \mathrm{M} \mathrm{NaCl}, 0.3 \mathrm{M}$ sodium citrate) overnight. After UV crosslinking, the membrane was incubated with the DIG-labeled $381 \mathrm{bp}$ probe for hybridization at $50^{\circ} \mathrm{C}$ for approx. $16 \mathrm{~h}$. After stringent washes, the transcript was visualized by chemiluminescence using CSPD (Roche, Mannheim, Ger- many) as a substrate. Negative control (without RNA) was also run to check the specificity of the transcript expression.

Peptide synthesis. A 31 amino-acid peptide corresponding to residues N-KLMPKIVSAIIYMVGQPNAGVTFLGHQCLVE-C (30-61) of SSAP was selected for synthesis after evaluating for B cell epitopes (http://tools.immuneepitope. org/tools/bcell/iedb_input) using the Kolaskar and Tongaonkar method and prediction of antimicrobial properties using the AMP database (http://aps. unmc.edu/AP/prediction/prediction_main.php). Peptides were synthesized co-linearly as a single molecule by the solid phase peptide synthesis using Fmoc amino acids on a full automated peptide synthesizer (Applied Biosystems, Foster City, CA, USA). Fmoc amino acids were activated using diisopropylcarbodiimide and hydroxybenzotriazole. Coupling was monitored for completion of the substitution using conductivity test and by estimation of the released Fmoc group at $324 \mathrm{~nm}$. TFAcleaved peptides were purified on a Waters C18 reversed phase column using a Pharmacia HPLC system. The peptide was eluted with a linear gradient of $0.1 \%$ TFA in water and $80 \%$ acetonitrile in $0.1 \% \mathrm{TFA}$ in water. The peptide collected as a single peak was lyophilized and used for immunization.

Antibody production. About $1 \mathrm{mg}$ of the peptide was coupled to keyhole limpet hemocyanin (Pierce, Rockford, IL, USA) following manufacturer's protocol. Two New Zealand White rabbits were immunized intraperitoneally with $200 \mu \mathrm{l}$ of phosphate buffered saline (PBS) containing $100 \mu \mathrm{g}$ of the peptide emulsified in complete Freund's adjuvant. The first immunization was followed by two boosts at 2-week intervals with aliquots of peptide emulsified in incomplete Freund's adjuvant. Antiserum was collected 10 days after the last injection. The anti-sera were checked by ELISA and the titres were found to be $1: 8000$. The specific anti-peptide antibody was purified via affinity chromatography over a cyanogen bromide-activated Sepharose column conjugated with the peptide fragment used as the immunogen.

Western blotting. S. serrata tissues were homogenized in a buffer containing $100 \mathrm{mM}$ Hepes, $\mathrm{pH}$ 7.0, $10 \mathrm{mM} \mathrm{MgCl}_{2}, 30 \mathrm{mM} \mathrm{NaCl}, 0.2 \mathrm{mM}$ phenylmethylsulfonyl fluoride (PMSF) and the proteinase inhibitor mix and centrifuged at 14000 r.p.m. for 15 min. About $100-150 \mu \mathrm{g}$ of proteins from various tissue lysates were separated on a $15 \%$ gel as described earlier. A colour protein mass ladder was loaded for reference. The proteins were transferred onto a nitrocellulose membrane and were incubated with anti-SSAP peptide rabbit polyclonal antibodies at a 1:100 dilution overnight, followed by horseradish 
peroxidase-conjugated anti-rabbit antibody (Sigma) at 1:1000. Bands were visualized by chemiluminescence using the ECL advance Western blotting detection kit (GE Healthcare, Buckinghamshire, UK).

\section{RESULTS}

\section{Identification of antimicrobial proteins}

Freshly prepared lysates of granular hemocytes containing about $49 \mathrm{mg}$ of protein were fractionated first on a CMC cation exchange resin. Fractions $(2 \mathrm{ml})$ were eluted in $0.2 \mathrm{M}$ ammonium acetate, lyophilized and tested for antibacterial activity (Fig. 1a). Fractions $29-32$ and 35 were found to contain detectable growth inhibiting activity against the four bacterial strains tested (E. coli, P. aeruginosa, S. aureus and S. pyogenes) as demonstrated by radial diffusion assay (Fig. 1b). The Gram negative bacteria (E. coli and P. aeruginosa) seem to be more susceptible to the fractions than Gram positive ones tested (S. aureus and S. pyogenes). The active fractions were pooled (about $7.86 \mathrm{mg}$ ) and low molecular mass

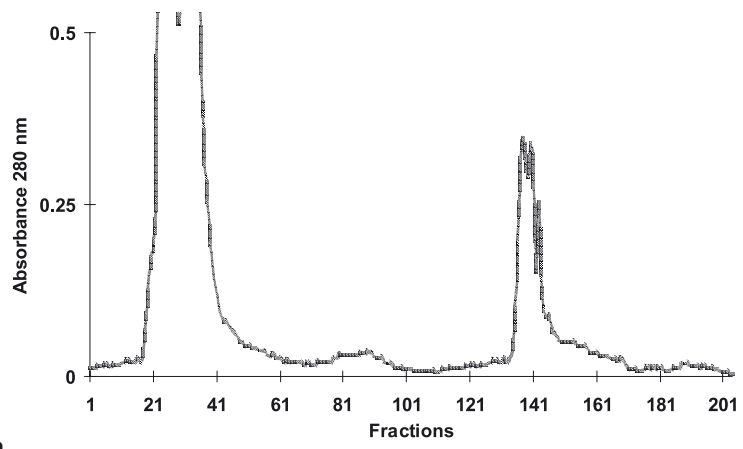

a

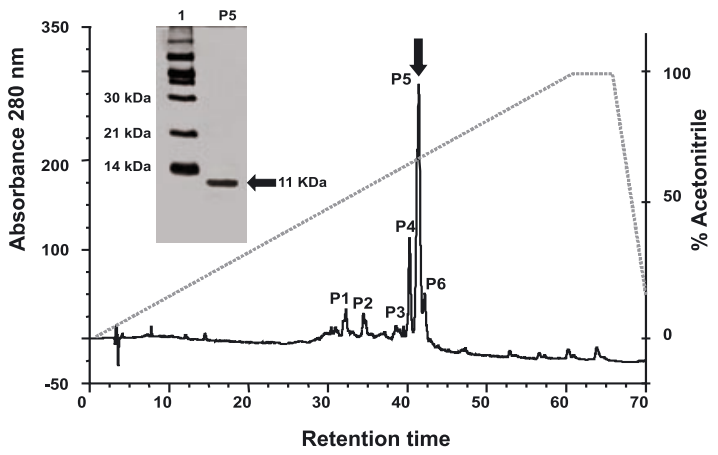

proteins were concentrated on an Amicon ultrafiltration unit with a $30 \mathrm{kDa}$ cut-off membrane. The filtrate (about $2.28 \mathrm{mg}$ ) was lyophilized, reconstituted with $0.1 \%$ TFA and loaded onto a $\mathrm{C}_{8}$ RP-HPLC column. The proteins were eluted in a three-step gradient as mentioned in Materials and Methods (Fig. 1c). The peaks (P1-P6) were collected, lyophilized and tested for antibacterial activity. Peak 5 demonstrated detectable antibacterial activity (Fig. 1d) and was re-loaded on the same column to check the homogeneity. The eluted fraction, silver stained on a $15 \%$ SDS/PAGE under denaturing conditions, showed the presence of a single protein band with a mobility corresponding to a molecular mass close to about $11 \mathrm{kDa}$ (Fig. 1c) and was named SSAP.

\section{Protein sequencing of SSAP}

Following trypsin digestion, cysteine stabilization and HPLC, three fractions were sequenced by automated Edman degradation. The sequence of one peptide was VELEALK and the sequences of other two peptides were QPDGFYTAK and NFVQTASNYK.
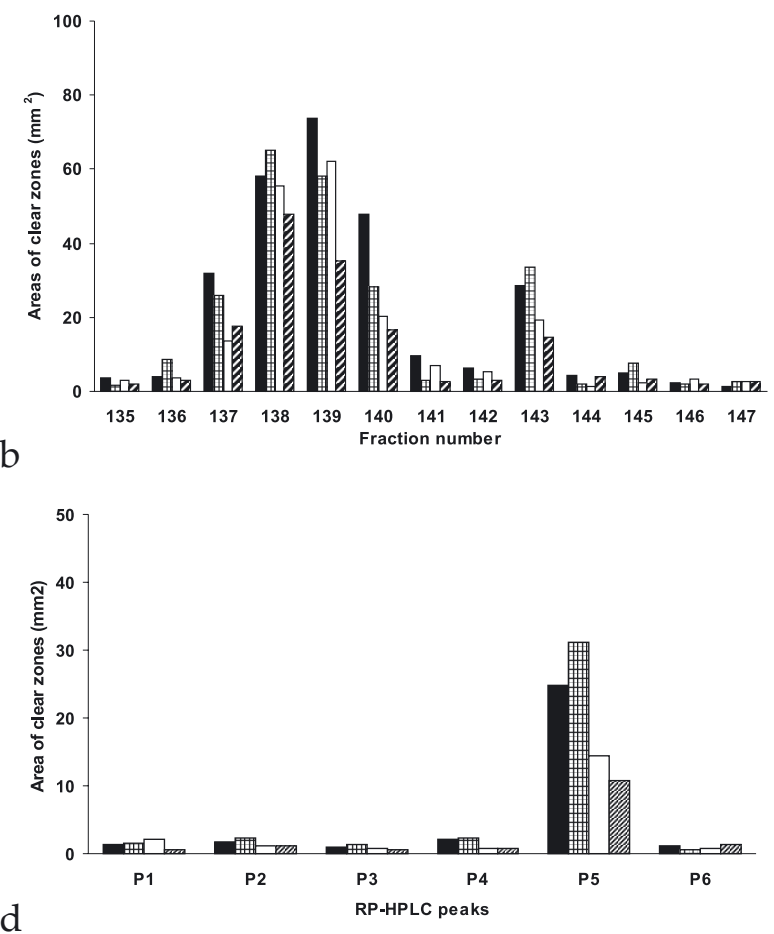

Figure 1. Purification and antimicrobial characterization of SSAP from granular hemocyte lysate of S. serrata.

(a) Protein profiles of dialyzed granular hemocyte lysates of S. serrata applied onto a CMC column. Unbound fractions were washed with $0.2 \mathrm{M}$ sodium acetate $(2 \mathrm{ml}$ fractions) until about $214 \mathrm{ml}$ of buffer passed through the column. Bound fractions were eluted with $0.2 \mathrm{M}$ ammonium acetate. (b) Antimicrobial activity of fractions (2 ml) were tested against Gram negative E. coli (black fill) and P. aeruginosa (square fill), and Gram positive S. aureus (white fill) and S. pyogens (crossed fill), by the modified radial diffusion assay and expressed as area of inhibition $\left(\mathrm{mm}^{2}\right)$. (c) Elution pattern of proteins $\leq 30 \mathrm{kDa}$, concentrated by ultrafiltration, separated on a Vydac $\mathrm{C}_{8} \mathrm{RP}-\mathrm{HPLC}$ column equilibrated with $0.1 \%$ (v/v) TFA/water. Elution $(1 \mathrm{ml} / \mathrm{min})$ was performed according to the procedure described in the experimental section. Peak P5 demonstrated a strong antimicrobial activity as tested by the modified radial diffusion assay against the bacteria described above (d). The active fraction showed a single protein band of $11 \mathrm{kDa}$ on SDS/PAGE (inset of Fig. 1c.) 


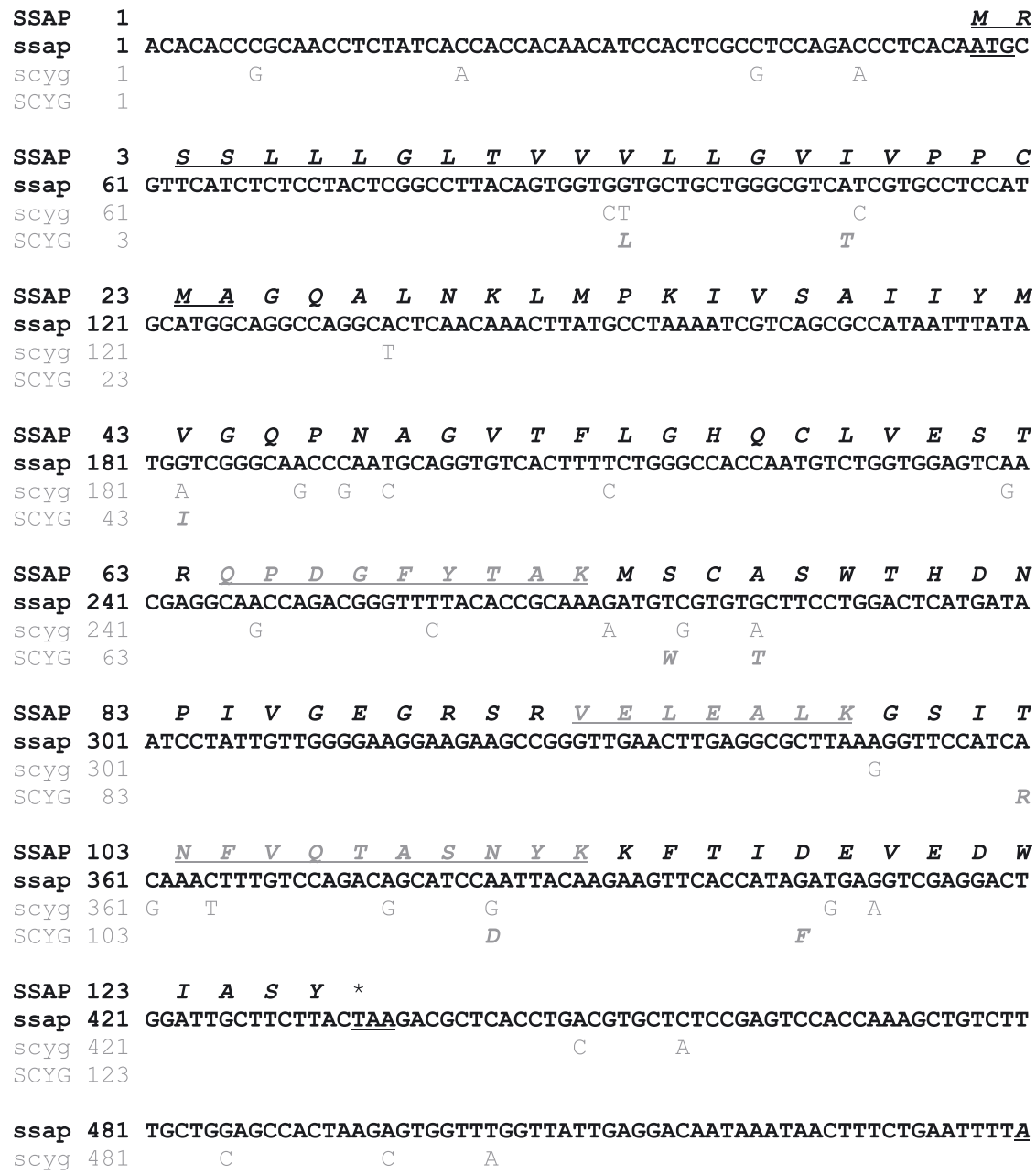

ssap 541 AAAAAAAAAAAAAAAAAAAAAAAA
Figure 2. The SSAP cDNA nucleotide sequence (ssap) and the predicted amino-acid sequence (SSAP) in comparison with scygonadin cDNA nucleotide (scyg) and amino-acid sequence (SCYG).

The numbers on the left of the sequence indicate the position of the first nucleotide and amino acid on each line. The nucleotide and amino acid substitutions in scygonadin compared to SSAP are denoted appropriately in grey fonts. The signal peptide sequence, polyadenylation signal and the stop codon are underlined in black. The partial amino-acid sequences obtained by Edman degradation are underlined in grey. The cDNA sequence has been deposited in the GenBank at accession number EF137865.
Cloning and sequencing of SSAP gene

From the peptides PDGFYT and ELEALK, two degenerate primers, DF and DR, were designed, respectively, and a $103 \mathrm{bp}$ fragment of cDNA was amplified by RT-PCR from hemocytes of $S$. serrata. Based on the sequence obtained, primers (SF and SR) were designed and using the $5^{\prime}$ and $3^{\prime}$ RACE PCR approaches, 370 and $332 \mathrm{bp}$ cDNA fragments were amplified, respectively, and the products were cloned and sequenced. The full-length $S$. serrata SSAP cDNA sequence was obtained by overlapping three cDNA fragments. The complete cDNA sequence and the deduced amino-acid sequence of SSAP of S. serrata are shown in Fig 2. The full-length SSAP cDNA consisted of $553 \mathrm{bp}$, containing an ORF of $381 \mathrm{bp}$, a $49 \mathrm{bp} 5^{\prime}$ untranslated region, and a $123 \mathrm{bp} \mathrm{3}$ ' untranslated region with a poly A signal. When compared with the complete non-redundant GenBank database using BLAST program, the SSAP cDNA sequence showed a high identity with scygonadin $(94 \%)$ and scygonadin 2 precursor $(77 \%)$. The translated protein sequence demonstrated signifi- cant homology with scygonadin (92\%), scygonadin 2 precursor $(64 \%)$ and anti-lipopolysaccharide factor (ALF) $(29-35 \%)$ from various marine invertebrates (Table 1). Scygonadin is about $10.8 \mathrm{kDa}$ anionic protein isolated from the male reproductive tract of S. serrata that inhibited growth of Micrococcus luteus and Aeromonas hydrophila and the gene coding for scygonadin has been well characterized (Huang et al., 2006).

Based on the deduced polypeptide sequence, SSAP was found to be composed of 126 amino acids, including a 24 amino-acid signal sequence predicted by SignalP software (ExPASy) in the N-terminal region of the polypeptide chain. Therefore, the mature SSAP is composed of 102 amino-acids residues. Amino acids are numbered beginning with the first methionine (Fig. 2). The calculated molecular mass of the mature protein (102 amino acids) is 11435 Da with an estimated pI of 5.7. The SSAP cDNA sequence and deduced amino-acid sequence have been submitted to the NCBI GenBank as accession numbers EF137865 and ABM05493, respectively. 
(a)

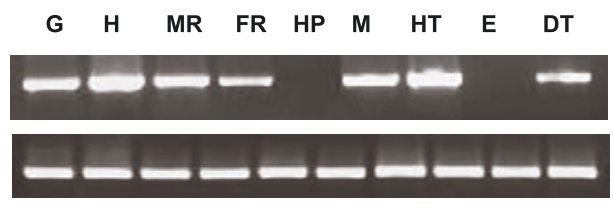

SSAP

(b)

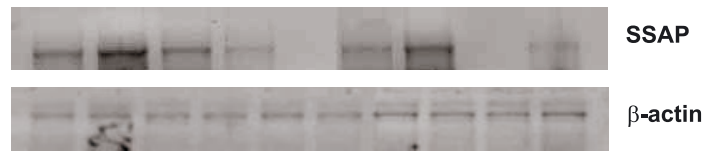

(c)

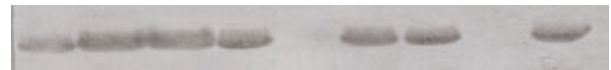

SSAP

Figure 3. SSAP gene and protein expression profiles of male and female crab tissues.

(a) Tissue expression profiles of SSAP as demonstrated by RT-PCR with primers OF and OR. Visible expression was observed for the following tissues: gills $(G)$, hemocytes $(\mathrm{H})$, male reproductive tract $(\mathrm{MR})$, female reproductive tract (FR), muscle (M), heart (HT) and digestive tract (DT). No expression was seen in hepatopancreas (HP) and eyes (E). A strong signal was observed for $\beta$-actin in all tissues analyzed. A similar expression pattern was observed with Northern hybridization (b), with a visible signal at about $550 \mathrm{bp}$ (SSAP) and about $650 \mathrm{bp}$ ( $\beta$-actin), respectively. (c) Western blot analysis with a polyclonal antibody raised against a peptide corresponding to residues 30-61 of SSAP demonstrated a strong signal at about $11 \mathrm{kDa}$ for $\mathrm{G}, \mathrm{H}$, MR, FR, M, HT and DT. No signal was observed for HP and $\mathrm{E}$.

Expression profile by RT-PCR, Northern and Western blot

A one step RT-PCR with ORF-specific primers (OF/OR) and RNA from various tissues: gills, heart, hepatopancreas, reproductive tract, muscle, hemocytes and eyes, led to the amplification of about 381 bp expected fragment. While hemocytes, gills and reproductive tract produced a strongly expressed transcript, muscle, heart and digestive tract showed a comparatively weaker expression. No expression of SSAP gene was observed in hepatopancreas and eyes (Fig. 3a). A strong about $200 \mathrm{bp}$ signal for $\beta$ actin was observed for all the tissues tested. Similar results were observed when the DIG-labeled about 380 bp PCR product was used to probe total RNA from various tissues transferred onto nylon membrane after separating on $1 \%$ formamide gel. The blot showed the presence of a strong, single transcript at about 550 bp (Fig. 3b). The detected fragment could be the complete mRNA (553 bp) coding for the SSAP gene including the $381 \mathrm{bp}$ ORF sequence along with the $5^{\prime}$ and $3^{\prime}$ untranslated regions. Again, about $650 \mathrm{bp} \beta$-actin transcript was observed in all tissues. Nitrocellulose membrane blots of tissue lysate proteins incubated with anti-SSAP peptide antibodies expressed a clear signal at about $11 \mathrm{kDa}$ for multiple tissues. Analogous to the results obtained by RTPCR and Northern blot, no signal was obtained for heaptopancreas and eyes (Fig. 3c).

\section{Antimicrobial characterization of the protein}

The MIC assay with SSAP clearly demonstrated detectable antimicrobial activity against both Gram positive and Gram negative bacteria (Table 2). The higher susceptibility of Gram negative bacteria E. coli and P. aeruginosa as compared to the Gram positive $S$. aureus and $S$. pyogenes clearly indicates the possibility of SSAP being target-specific (e.g., against lipopolysaccharides) in respect to its antimicrobial activity. Similar experiments need to be performed with a broader panel of microorganisms including filamentous fungi and yeast.

\section{DISCUSSION}

The present study documents the presence of about $11 \mathrm{kDa}$ antimicrobial protein, SSAP, in granular hemocytes of the Indian mud crab S. serrata. The protein demonstrated a significant sequence homology with that of scygonadin, also identified from $S$. serrata, both at the cDNA and protein level and displayed antimicrobial properties against both Gram-positive and Gram-negative bacteria. Yet there are significant differences observed at the tissue

Table 1. Homology of SSAP cDNA sequence with other sequences in the GenBank as analyzed using BLAST.

It is interesting to note that all the proteins highlighted in the BLAST search are known to have antimicrobial properties.

\begin{tabular}{|c|c|c|c|c|}
\hline Protein & Organism & $\begin{array}{l}\text { NCBI accession } \\
\text { number }\end{array}$ & $\begin{array}{l}\text { Number of } \\
\text { amino acids }\end{array}$ & Homology (\%) \\
\hline Scygonadin precursor & S. serrata & AAW57403.1 & 126 & 92 \\
\hline Scygonadin 2 precursor & S. serrata & ABI96918.1 & 124 & 64 \\
\hline Anti-lipopolysaccharide factor (ALF) & Litopenaeus schmitti & ABJ90465.1 & 123 & 30 \\
\hline ALF & Penaeus monodon & ABP73291.1 & 120 & 29 \\
\hline ALF & Pacifastacus leniusculus & ABQ12866.1 & 120 & 29 \\
\hline $\mathrm{ALF}$ & Farfantepenaeus paulensis & ABQ96196.1 & 79 & 35 \\
\hline ALF & Tachypleus tridentatus & AAK00651 & 103 & 32 \\
\hline ALF & Limulus polyphemus & P07086 & 101 & 33 \\
\hline ALF & S. paramamosain & ABP96981 & 123 & 23 \\
\hline
\end{tabular}




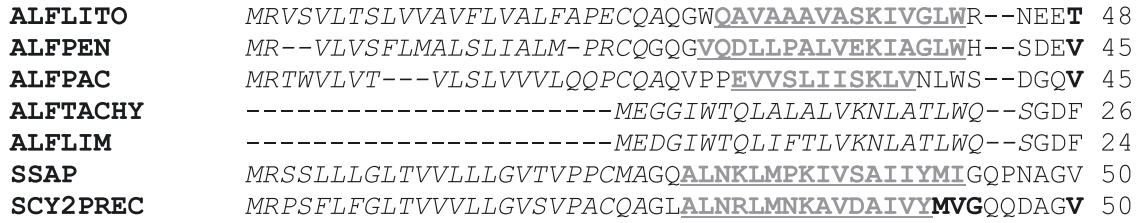

ALFLITO
ALFPEN
ALFPAC
ALFTACHY
ALFLIM
SSAP
SCY2 PREC

ALFLITO

ALFPEN

ALFPAC

ALFTACHY

ALFLIM

SSAP

SCY2PREC

\begin{abstract}
48

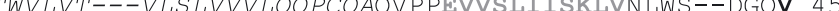
MRPSFLFGLTVVVLLGVSVPACQAGLALNRLMNKAVDAIVYMVGQQDAGV 50
\end{abstract}

ELLGHKCRFTVKPYIKRLQLHYKGKMWCPGWTPIT---GEARTRSHSGVA 95 EFLGHSCRYSQRPSFYRWELYFNGRMWCPGWAPFT---GRSRTRSPSGAI 92 EFMGHTCNYSYSPTISKFQLYYKGKMWCPGWAPFS---GNSKTKSRAGSI 92 QFLGHECHYRVNPTVKRLKWKYKGKFWCPSWTSIT---GRATKSSRSGAV 73 QFLDHECHYRIKPTFRRLKWKYKGKFWCPSWTSIT---GRATKSSRSGAV 71 TFLGHQCLVES---TRQPDGFYTAKMWCTSWTSDNPIVGEGRSRVELEAL 97 SLLGHPCLVES---AKQPEGIYTAVMSCASWTPR--FVGEGTSEVELEAL 95 $:{ }^{\star} \star \quad:$ : . : ${ }^{\star} \ldots{ }^{\star}: . \quad{ }^{\star} .$.

GRTARDFVQKAFERGLISEQDAKRWLSS-- 123 EHATRDFVOKALOSNLITEEDARIWLEH-- 120 EHATRDFVTKAIDQKLITAEQASAWIKN-- 120 EHSVRDFVGOAKSSGLITEKEAOTFISQYQ 103 EHSVRNFVGQAKSSGLITQRQAEQFISQYN 103 KGSIRNFVOTASDYKKFTIEEVEDWIASY - 126 KGSIRSFIRKASDYQLLSKEDLEDWLASY - 124 : *. ${ }^{\star}:$ * : : : : : :
Figure 4. Multiple sequence alignment with Clustal $\mathrm{W}$ and secondary structure prediction with JPred of SSAP and related proteins.

Analyzed were: anti-lipopolysaccharide factor (ALF) L. schmitti (ABJ90465.1), ALF P. monodon (ABP73291.1), ALF P. leniusculus (ABQ12866.1), ALF T. tridentatus (AAK00651), ALF L. polyphemus (P07086), SSAP S. serrata (ABM05493.1), scygonadin 2 precursor S. serrata (ABI96918.1). The numbers on the right of the sequence indicate the position of the last amino acid for a protein in each line. The secretory signal sequences predicted by SiganlP are denoted in italics, the predicted $\alpha$-helical domains are in bold grey (underlined) and the predicted $\beta$-sheets are highlighted in bold black. expression level and the physical properties of the protein. Granular hemocytes were used as a source for isolation of proteins as it generated a higher yield of active protein for a given amount of starting material than with whole hemolymph. A similar approach was used earlier to isolate a cysteine-rich antibacterial protein from the shore crab Carcinus maenas (Schnapp et al., 1996).

It is interesting to note that SSAP showed $94 \%$ sequence homology with scygonadin, both at the nucleotide and amino-acid level. Scygonadin was reported as a $10.8 \mathrm{kDa}$ antibacterial protein isolated from the seminal plasma of S. serrata (Huang et al., 2006). Further studies with RT-PCR and Northern blot established the expression of the scygonadin gene as male-specific, with tissue expression limited to the ejaculatory duct (Wang et al., 2007). Analogous to scygonadin, the full length cDNA sequence of SSAP is also composed of about $539 \mathrm{bp}$ and codes for a 126 amino-acid molecule with a 24 amino-acid signal peptide and a 102 amino-acid mature protein. Full length cDNA sequence comparisons of SSAP with that of scygonadin showed 33 nucleotide substitutions of which a few led to amino acid changes at 8 residues (Fig. 2). These alterations justify the difference in the calculated mass and the $\mathrm{pI}$ of the two proteins. While SSAP demonstrates a mass and pI of $11435 \mathrm{Da}$ and 5.77, respectively, scygonadin displayed a mass of 11271.8 Da and a pI of 6.09.

While scygonadin is expressed exclusively in the male crabs and limited to the ejaculatory duct, SSAP is expressed in multiple tissues of both male and female crabs. In crabs of either sex, hemocytes, gills and reproductive tract showed a stronger expression both at protein and RNA level as evidenced by Western and Northern blots, respectively. It has been documented that both hemocytes and gills of marine animals play a very important role in regulating the innate immune mechanisms to combat microbial invasion. Hemocytes are known to be a rich source of antimicrobial proteins and peptides, and exhibit a complex system of innate defense mechanisms involving cellular and humoral responses influenced by the presence of microbial components such as lipopolysaccharides (LPS) or $\beta$-1,3-glucans, once pathogens gain entry into the hemocoel of the host (Lee \& Soderhall, 2002; Iwanaga \& Lee, 2005). Similarly, gills in marine organisms are covered with only a single layer of mucus-lined fragile cells and, being constantly flushed with water, that may contain pathogens, constituting a very important site of pathogen entry. Therefore, potent AMP can be expected to be found in gills to prevent such an entry as reported in several species including fish and crabs (Smith \& Ratcliffe, 1989; Iijima et al., 2003).

There is also strong evidence for regulated expression of AMPs in the male and female reproductive tracts of various species. Andropin from male Drosophila melanogaster, ceratotoxin from fe-

Table 2. The antibacterial activity of purified SSAP determined as MIC.

Serial dilutions of SSAP $\left(6.25-200 \mu \mathrm{g} \mathrm{ml} \mathrm{m}^{-1}\right)$ were tested against bacteria. MIC are expressed as the interval $a-b$, where $a$ is the highest concentration tested at which microorganisms are able to grow and $b$ the lowest concentration that causes $100 \%$ growth inhibition.

\begin{tabular}{ll}
\hline Microorganism & MIC range $\left(\mu \mathrm{g} \mathrm{ml} \mathrm{m}^{-1}\right)[a-b]$ \\
\hline Escherichia coli & $25-50$ \\
Pseudomonas aeruginosa & $12.5-25$ \\
Staphylococcus aureus & $50-100$ \\
Streptococcus pyogenes & $25-50$
\end{tabular}


male medfly Ceratitis capitata and $\beta$-defensins from humans and rhesus are good examples (Samakovlis et al., 1991; Marchini et al., 1995; Quayle et al., 1998; Harder et al., 2001). The expression and functions of other AMPs expressed in human reproductive tracts have also been reviewed elsewhere (Hall et al., 2002; Wira \& Fahey, 2004).

Wang and his group (2007) have studied the expression of scygonadin in male gonads of three groups of animals based on their body mass: small $(46.33 \pm 1.53 \mathrm{~g})$, medium $(112.67 \pm 10.02 \mathrm{~g})$ and large or mature $(216.33 \pm 34.39 \mathrm{~g})$. While in the small and medium groups of animals no scygonadin transcripts were detected owing to underdevelopment of the gonads, the expression was quite strong in large animals inferred to possess mature and developed gonads. In our study, the animals of either sex weighed around $193.56 \pm 27.04 \mathrm{~g}$, which located them between the medium and large category as described above.

Apart from the high identity of SSAP with scygonadin, it is of interest to note that the protein shows a significant sequence homology $(30-35 \%)$ to a family of proteins known as anti-lipopolysaccharide factor (ALF). ALFs are small proteins that can bind and neutralize lipopolysaccharide (LPS). The proteins described in Table 1 were aligned using CLUSTAL W (http://www.ebi.ac.uk/tools/clustalw2) and their secondary structures predicted from amino-acid sequences with the JPRED tool (http://www. compbio.dundee.ac.uk/ www-jpred). The results described in Fig. 4 clearly highlight the common features among the listed proteins, namely the presence of a fairly conserved secretory signal sequence, appropriately placed $\alpha$-helical and $\beta$-sheet domains and highly conserved cysteine residues.

The first ALF, originally called LALF, a 11.8 $\mathrm{kDa}$ protein identified from the amebocyte of the horseshoe crab Limulus polyphemus was shown to bind and neutralize LPS and demonstrated a strong antibacterial effect on Gram-negative R-type bacteria (Morita et al., 1985). Recently, several ALFs have been isolated and characterized from hemocytes in several species of shrimps, while some were discovered from an EST library of the shore crab C. maenas and the blue crab C. sapidus (Towle \& Smith, 2006; Imjongjirak et al., 2007). Recently, Imjongjirak and colleagues (2007) have been successful in isolating a full-length cDNA encoding for an $11.18 \mathrm{kDa}$ ALF protein (ALFSp) from hemocytes of mud crab, Scylla paramamosain. Tissue distribution analysis revealed that ALFSp was abundantly expressed in hemocytes, intestine, and muscle but not in eyestalk, and a synthetic ALFSp peptide containing putative LPS binding domain revealed a strong antimicrobial activity against Micrococcus luteus and Vibrio harveyi (Imjongjirak et al., 2007). It is still not known if $S$. serrata expresses a homolog of ALFSp in either of its tissues. But an interesting observation from the MIC studies was the increased susceptibility of Gram negative bacteria, E. coli and P. aeruginosa to SSAP compared to Gram positive S. aureus and S. pyogenes. Further experiments will have to be executed to analyze if SSAP has LPS binding properties.

It is unclear why SSAP and scygonadin demonstrate differential tissue expression in spite of their almost full identity at the protein and cDNA levels. One possibility is that SSAP could possibly be an isoform or a differentially expressed variant of scygonadin with the expression influenced by factors present in the tissue. Similar observations were made by Zhao and colleagues (1999) where goat defensin precursors GBD-1 and GBD-2, identical in $96.8 \%$ of their bases and $88.2 \%$ of their amino acids, exhibited differential expression in the digestive and respiratory tracts. In yet another study, Huttner and colleagues (1998) detected two distinct sheep $\beta$-defensin cDNA sequences, SBD1 and SBD2, which shared $87 \%$ identity at the nucleotide level and $78 \%$ identity at the protein level. While both the isoforms were expressed with same intensity at 130 day gestation period, the gene expression varied in adult animals, with SBD1 expression retained in multiple tissues of the digestive tract and that of SBD2 restricted to ileum and colon. Further experiments are warranted to elucidate if SSAP is a variant of scygonadin and if they demonstrate different tissue expression patterns as described above.

The partially purified protein fractions obtained from ion exchange chromatography and RPHPLC were tested against bacterial isolates from vagina of patients tested positive for $B V$. BV is a common condition with numerous health problems affecting millions of women annually, characterized by an alteration of genital tract flora and associated with increased susceptibility to HIV infection (Spear et al., 2007). The intention of testing the identified protein against bacteria involved in BV was to develop the molecule as a microbicide to combat the spread of sexually transmitted infection (STI)-causing pathogens, including HIV. Microbicides are anti-infective preparations for topical self-administration prior to sexual intercourse to protect against the transmission of HIV and other STIs and recently AMPs have been analyzed for their use as a microbicide. Excellent reviews suggest that AMPs can be highly effective in inhibting the growth of STI-causing pathogens and HIV (Reddy et al., 2004; Cole, 2005).

SSAP is similar to many other AMPs as they are translated with a signal, mature and a propiece domain (Hughes \& Yeager, 1997). The translated protein sequence of SSAP is composed of a sig- 
nal peptide of 24 amino acids with a hydrophobicity of $62.5 \%$ which is an ideal characteristic of such sequences. It is followed by a mature protein sequence of 102 amino acids with a high concentration of negatively charged residues in the C-terminal, a characteristic of an anionic propiece seen in many mature AMPs. It is generally proposed that the anionic properties of the propiece help in neutralizing the cytotoxicity of the mature protein or peptide until required in vivo (Hughes \& Yeager, 1997). The net charges of SSAP were calculated as +2 based on the number of positively (arginine, histidine and lysine) and negatively charged residues (aspartic and glutamic acids). It could be postulated that the cytotoxicity of the protein is attributed to the overall net positive charge and a high content of hydrophobic residues $(51 \%)$ at the $\mathrm{N}$-terminal region of the mature protein. It is likely that SSAP, like other cationic peptides, might be able to bind to anionic components of microbial membranes and kill them by formation of pores or by permeabilizing the cell membranes (Brogden, 2005).

In summary, it can be concluded from our study that SSAP is a multi-tissue expressed antimicrobial protein that demonstrates antibacterial properties in vitro. However, it is unclear if the protein demonstrates similar defense properties against invading microbes in vivo or if it has any role in the development of the animal. Further experimentation is required to understand the nature of induction of SSAP in response to microbial invasion and also to study the exact mechanism of its action. Future studies will be aimed at expressing the protein in a suitable recombinant system enabling the production of larger amounts of active protein to carry out the above-mentioned experiments.

\section{Acknowledgements}

The authors thank the Director NIRRH for giving continued encouragement in carrying out the study. This work was supported by grants received from CONRAD program and Indian Council of Medical Research (ICMR). We also thank Council of Scientific and Industrial Research (CSIR) for providing Senior Research Fellowship to RDY.

We also thank Mr. Mangesh Malvankar for secretarial assistant.

\section{REFERENCES}

Andreu D, Rivas L (1998) Animal antimicrobial peptides: an overview. Biopolymers 47: 415-433.

Bradford MM (1976) A rapid and sensitive method for the quantification of microgram quantities of protein utilizing the principle of dye binding. Anal Biochem 72: 248-254.
Brogden KA (2005) Antimicrobial peptides: pore formers or metabolic inhibitors in bacteria? Nat Rev Microbiol 3: 238-250.

Casteels P, Ampe C, Jacobs F, Tempst P (1993) Functional and chemical characterization of Hymenoptaecin, an antibacterial polypeptide that is infection induced in the honeybee (Apis mellifera). J Biol Chem 268: 7044-7054.

Chattopadhyay T, Chatterjee B (1997) Further biochemical and biophysical characterisation of scyllin, Scylla serrata hemolymph lectin. Biochem Mol Biol Int 42: 183-191.

Cole AM (2005) Antimicrobial peptide microbicides targeting HIV. Protein Pept Lett 12: 41-47.

Cooper EL (1985) Overview of humoral factors in invertebrates. Dev Comp Immunol 9: 577-583.

Hall SH, Hamil KG, French FS (2002) Host defense proteins of the male reproductive tract. J Androl 23: 585-597.

Harder J, Bartels J, Christophers E, Schröder J-M (2001) Isolation and characterization of human $\beta$-defensin-3, a novel human inducible peptide antibiotic. $J$ Biol Chem 276: 5707-5713.

Hoq MI, Seraj MU, Chowdhury S (2003) Isolation and characterization of antimicrobial peptides from the mud crab, Scylla serrata. Pakistan J Biol Sci 6: 1345-1353.

Huang WS, Wang KJ, Yang M, Cai JJ, Li SJ, Wang GZ (2006) Purification and part characterization of a novel antibacterial protein scygonadin, isolated from the seminal plasma of mud crab, Scylla serrata (Forskal). J Exp Mar Boil Ecol 339: 37-42.

Hudson DA, Lester RJG (1994) Parasites and symbionts of wild mud crabs, Scylla serrata (Forskal) of potential significance in aquaculture. Aquaculture 120: 183-199.

Hughes AL, Yeager M (1997) Coordinated amino acid changes in the evolution of mammalian defensins. J Mol Evol 44: 675-682.

Huttner KM, Brezinski-Caliguri DJ, Mahoney MM, Diamond G (1998) Antimicrobial peptide expression is developmentally regulated in the ovine gastrointestinal tract. J Nutrition 128: 297S-299S.

Iijima N, Tanimoto N, Emoto Y, Morita Y, Uematsu K, Murakami T, Nakai T (2003) Purification and characterization of three isoforms of chrysophsin, a novel antimicrobial peptide in the gills of the red sea bream, Chrysophrys major. Eur J Biochem 270: 675-686.

Imjongjirak C, Amparyup P, Tassanakajon A, Sittipraneed S (2007) Antilipopolysaccharide factor (ALF) of mud crab Scylla paramamosain: molecular cloning, genomic organization and the antimicrobial activity of its synthetic LPS binding domain. Mol Immunol 44: 31953203.

Iwanaga S, Lee BL (2005) Recent advances in the innate immunity of invertebrate animals. Biochem Mol Biol 38: $128-150$.

Janeway Jr CA, Medzhitov R (2002) Innate immune recognition. Annu Rev Immunol 20: 197-216.

Jiravanichpaisal P, Lee BK, Soderhall K (2006) Cell-mediated immunity in arthropods: hematopoiesis, coagulation, melanization and opsonization. Immunobiology 211: 213-236.

Kurtz J (2005) Specific memory within innate immune systems. Trends Immunol 26: 186-192.

Laemmli UK (1970) Cleavage of structural proteins during the assembly of the head of bacteriophage T4. Nature 227: 680-685.

Lee SY, Soderhall K (2002) Early events in crustacean innate immunity. Fish Shellfish Immunol 12: 421-437.

Lehrer RI, Ganz T (1999) Antimicrobial peptides in mammalian and insect host defense. Curr Opin Immunol 11: 23-27. 
Marchini D, Manetti AGO, Rosetto M, Bernini LF, Telford JL, Baldari CT, Dallai R (1995) cDNA sequence and expression of the ceratotoxin gene encoding an antibacterial sex-specific peptide from the medfly Ceratitis capitata (Diptera). J Biol Chem 270: 6199-6204.

Mitta G, Vandenbulcke F, Noel T, Romestand B, Beauvillain JC, Salzet M, Roch P (2000) Differential distribution and defense involvement of antimicrobial peptides in mussel. J Cell Sci 113: 2759-2769.

Miyata T, Tokunaga F, Yoneya T, Yoshikawa K, Iwanaga S, Niwa M, Takao T, Shimonishi Y (1989) Antimicrobial peptides, isolated from horseshoe crab hemocytes, tachyplesin II and polyphemusins I and II: chemical structures and biological activity. J Biochem (Tokyo) 106: $663-668$.

Morita T, Ohtsubo S, Nakamura T, Tanaka S, Iwanaga S, Ohashi K, Niwa M. (1985) Isolation and biological activities of limulus anticoagulant (anti-LPS factor) which interacts with lipopolysaccharide (LPS). J Biochem 97: 1611-1620.

Murakami T, Niwa M, Tokunaga F, Miyata T, Iwanaga S (1991) Direct virus inactivation of tachyplesin-I and its isopeptides from horseshoe crab hemocytes. Chemotherapy 37: 327-334.

Quayle AJ, Porter EM, Nussbaum AA, Wang YM, Brabec C, Yip KP, Mok SC (1998) Gene expression, immunolocalization, and secretion of human defensin-5 in human female reproductive tract. Am J Pathol 152: 1247-1258.

Reddy KVR, Clara A, Gupta SM, Yedery RD (2004a) Evaluation of antimicrobial peptide, Nisin as a safe vaginal contraceptive agent in rabbits: in vitro and in vivo studies. Reproduction 128: 126-137.

Reddy KVR, Yedery RD, Clara A (2004b) Antimicrobial peptides: premises and promises. Int $J$ Antimicrobial Agents 24: 536-547.

Relf JM, Chisholm JRS, Kemp GD, Smith VJ (1999) Purification and characterization of a cysteine-rich $11.5 \mathrm{kDa}$ antibacterial protein from the granular hemocytes of the shore crab, Carcinus maenas. Eur J Biochem 264: 350357.

Samakovlis C, Kylsten P, Kimbrell DA, Engström A, Hultmark D (1991) The andropin gene and its product, a male-specific antibacterial peptide in Drosophila melanogaster. EMBO J 10: 163-169.

Samonte GPB, Agbayani RF (1992) Pond culture of mud crab (Scylla serrata) and economic analysis, SEAFDEC. Asian Aquaculture 14: 3-5.

Schnapp D, Kemp GD, Smith VJ (1996) Purification and characterization of a proline rich anti-bacterial peptide, with sequence similarity to bactenecin 7 , from the hemocytes of the shore crab, Carcinus maenas. Eur J Biochem 240: 532-539.

Smith VJ, Ratcliffe NA (1980) Defensive reactions of the shore crab, Carcinus maenas. In vivo haemocytic and histopathological responses to injected bacteria. J InvPathol 35: $65-74$

Soderhall K, Smith VJ (1983) Separation of hemocytes of Carcinus maenas and other decapod crustaceans and phenoloxidase distribution. Dev Comp Immunol 7: 229239.

Spear GT, StJohn E, Zariffard MR (2007) Bacterial vaginosis and human immunodeficiency virus infection. AIDS Res Therapy 4: 25.

Towle DW, Smith CM (2006) Gene discovery in Carcinus maenas and Homarus americanus via expressed sequence tags. Integ Comp Biol 46: 912-918.

Wang KJ, Huang WS, Yang M, Chen HY, Bo J, Li SJ, Wang GZ (2007) A male-specific expression gene, encodes a novel anionic antimicrobial peptide, scygonadin, in Scylla serrata. Mol Immunol 44: 1961-1968.

Wira CR, Fahey JV (2004) The innate immune system: gatekeeper to the female reproductive tract. Immunology 111: $13-15$.

Yedery RD, Reddy KVR (2005) Antimicrobial peptides as microbicidal contraceptives: prophecies for prophylactics. Eur J Contracept Reprod Health Care 10: 32-42.

Zasloff M (1987) Magainins, a class of antimicrobial peptides from Xenopus skin: isolation, characterization of two active forms, and partial cDNA sequence of a precursor. Proc Natl Acad Sci USA 84: 5449-5453.

Zhao C, Nguyen T, Liu L, Shamova O, Brogden K, Lehrer RI (1999) Differential expression of caprine $\beta$-defensins in digestive and respiratory tissues. Infect Immun 11: 6221-6224. 